\title{
Adrenocortical carcinoma in children: First population-based clinicopathological study with long-term follow-up
}

\author{
T.M.A. KERKHOFS ${ }^{1}$, M.H.T. ETTAIEB ${ }^{1}$, R.H.A. VERHOEVEN ${ }^{2}$, G.J.L. KASPERS ${ }^{3}$, W.J.E. TISSING ${ }^{4}$, \\ J. LOEFFEN ${ }^{5}$, M.M. VAN DEN HEUVEL-EIBRINK ${ }^{6}$, R.R. DE KRIJGER ${ }^{7,8}$ and H.R. HAAK ${ }^{1,9,10}$ \\ ${ }^{1}$ Department of Internal Medicine, Máxima Medical Centre, Eindhoven/Veldhoven; ${ }^{2}$ Department of Research, \\ Eindhoven Cancer Registry, Comprehensive Cancer Centre The Netherlands, Eindhoven; ${ }^{3}$ Department of Pediatric Oncology \\ and Hematology, VU University Medical Centre, Amsterdam; ${ }^{4}$ Department of Pediatric Oncology and Hematology, \\ University of Groningen, University Medical Centre Groningen, Groningen; ${ }^{5}$ Department of Pediatric Oncology \\ and Hematology, University Medical Central St. Radboud, Nijmegen; ${ }^{6}$ Department of Pediatric Oncology and Hematology, \\ Erasmus University Medical Centre - Sophia Children's Hospital, Rotterdam; ${ }^{7}$ Department of Pathology, \\ Reinier de Graaf Hospital, Delft; ${ }^{8}$ Department of Pathology, Erasmus University Medical Centre, Rotterdam; \\ ${ }^{9}$ Department of Internal Medicine, Division of General Internal Medicine, Maastricht University Medical Centre, \\ Maastricht; ${ }^{10}$ Department of Health Services Research and CAPHRI School for Public Health \\ and Primary Care, Maastricht University, The Netherlands
}

Received July 14, 2014; Accepted August 20, 2014

DOI: $10.3892 /$ or.2014.3506

\begin{abstract}
Adrenocortical carcinoma (ACC) is rare in both adult and pediatric populations. Literature suggests significant differences between children and adults in presentation, histological properties and outcome. The aim of this first nationwide study on pediatric ACC was to describe the incidence, presentation, pathological characteristics, treatment and survival in The Netherlands. All ACC patients aged $<20$ years at diagnosis and registered in the population-based Netherlands Cancer Registry between 1993 and 2010 were included. Clinical data were extracted from medical records. Archival histological slides were collected via the Dutch Pathology Registry (PALGA). We compared our findings to all clinical studies on pediatric ACC that were found on PubMed. Based on the results, 12 patients were identified: 8 females and 4 males. The median age was 4.1 years (range 1.1-18.6). The population-based age-standardized incidence rate for patients $<20$ years was 0.18 per million person-years. Autonomous hormonal secretion was present in 10 patients. Seven patients were aged $\leq 4$ years at diagnosis, 5 presented with localized disease and 2 with locally advanced disease. Five patients were aged $\geq 5$ years, 3 presented with distant metastases and 1 with locally advanced disease. For all
\end{abstract}

Correspondence to: Dr T.M.A. Kerkhofs, Department of Internal Medicine, Máxima Medical Centre, Ds. Th. Fliednerstraat 1, 5631 BM Eindhoven, The Netherlands

E-mail: t.kerkhofs@mmc.nl

Key words: adrenocortical carcinoma, pediatrics, incidence, cancer registry, histological characteristics, long-term follow-up patients, histological examination displayed malignant characteristics. All patients aged $\leq 4$ years at diagnosis survived; the median follow-up was 97 months (57-179 months). All patients aged $\geq 5$ years died; the median survival was 6 months (0-38 months). Pediatric ACC is extremely rare in the Western world. The clinical outcome was remarkably better in patients aged $\leq 4$ years. This is in accordance with less advanced stage of disease at presentation, yet contrasts with the presence of adverse histological characteristics. Clinical management in advanced disease is adapted from adult practice in the absence of evidence regarding pediatric ACC.

\section{Introduction}

Adrenocortical carcinoma (ACC) is a rare disease in both adult and pediatric patients. A recent population-based study estimated the incidence between 1.0 and 1.3 patients per million person-years (1). According to a study from the USA Surveillance, Epidemiology and End Results (SEER) database, the incidence is even lower among patients under 20 years of age: 0.2-0.3 patients per million (2).

Several case series demonstrated that pediatric patients with adrenocortical tumors more often present with symptoms of hormonal overproduction than adult patients. Virilization and precocious puberty are the most common symptoms, reported in $80-100 \%$ of patients (3-6).

Apart from differences in incidence and clinical presentation, there appear to be differences in biological behavior as well. Several authors reported significantly better outcomes in pediatric ACC patients compared to adult patients, even when tumors display similar malignant characteristics upon histological examination $(7,8)$. The overall 5 -year survival in the SEER study was $57 \%$ which is significantly higher than typical rates in adult populations which vary around $30-40 \%$ (2). 
Table I. Overview of the clinical signs and laboratory findings in 12 pediatric patients with adrenocortical carcinoma.

\begin{tabular}{|c|c|c|c|c|c|c|c|c|c|c|c|c|}
\hline \multirow[b]{2}{*}{ Patient case no. } & \multicolumn{7}{|c|}{ Age $\leq 4$ years } & \multicolumn{5}{|c|}{ Age $\geq 5$ years } \\
\hline & 1 & 2 & 3 & 4 & 5 & 6 & 7 & 8 & 9 & 10 & 11 & 12 \\
\hline Gender & $\mathrm{F}$ & $\mathrm{F}$ & $\mathrm{F}$ & $\mathrm{F}$ & $\mathrm{F}$ & M & M & $\mathrm{F}$ & $\mathrm{F}$ & $\mathrm{F}$ & M & F \\
\hline \multicolumn{13}{|l|}{ Clinical signs } \\
\hline Moonface & - & + & - & - & - & - & - & + & - & + & 0 & + \\
\hline Acne & - & + & + & 0 & - & - & - & + & - & - & 0 & - \\
\hline Hirsutism & + & 0 & + & + & + & + & 0 & + & 0 & 0 & 0 & 0 \\
\hline Enlarged genitalia & + & + & + & + & + & + & + & + & - & - & 0 & 0 \\
\hline Increased height & - & + & + & - & + & + & + & 0 & - & - & 0 & 0 \\
\hline \multicolumn{13}{|l|}{ Laboratory findings } \\
\hline Cortisol & - & - & $=$ & + & - & $=$ & $=$ & + & + & $=$ & 0 & + \\
\hline Testosterone & + & + & + & + & + & + & + & + & + & + & 0 & + \\
\hline DHEAS & + & + & + & + & + & + & $=$ & + & 0 & + & 0 & + \\
\hline Androstenedione & + & + & + & + & + & + & + & + & $=$ & + & 0 & + \\
\hline Estradiol & 0 & 0 & $=$ & $=$ & + & 0 & 0 & - & 0 & $=$ & 0 & + \\
\hline
\end{tabular}

DHEAS, dehydroepiandrosterone sulphate; F, female; M, male. Clinical signs: + present; - absent; 0 unknown. Laboratory findings: + increased; - decreased; = within reference interval; 0 unknown.

Moreover, survival in pediatric populations appears to be strongly correlated to age; survival rates $>80 \%$ are reported in subgroups where age at presentation is $<4$ years $(2,4)$. Following the observed discrepancy between clinical outcome and histological characteristics, there are no clear-cut pathological criteria for malignancy in pediatric adrenocortical tumors, whereas adult tumors can be adequately classified based on the Weiss or Van Slooten scores (8-10).

This uncertainty poses a problem for clinicians that are confronted with suspect adrenal tumors in pediatric patients. The need for surgical resection in the case of localized disease is evident, yet the necessity of adjuvant therapy remains elusive. Moreover, in metastasized disease, evidence on treatment options is scarce. Recently published results from the German GPOH-MET 97 trial emphasize the importance of radical surgery in localized disease and suggest that chemotherapy (vincristine/ifosfamide/adriamycin or carboplatin/VP16) in combination with mitotane could yield a survival benefit in metastasized disease $(3,11)$.

The aim of the present study was to investigate the incidence, clinical presentation, pathological characteristics, treatment and clinical outcome of pediatric ACC in The Netherlands. Our primary objective was to assess the magnitude of the problem by describing the population and current clinical management. Our secondary objective was to identify possible prognostic factors by investigating whether there are clinical or histological characteristics correlated with clinical outcome.

\section{Materials and methods}

The Netherlands Cancer Registry (NCR) is a nationwide, population-based registry containing data on cancer patients diagnosed since 1989. The NCR contains data on all patients with histopathologically proven disease, as well as most patients with cancer diagnosed otherwise. Completeness of case ascertainment is estimated to be at least $95 \%$. Topography and histology were coded according to the International Classification of Diseases for Oncology. All tumors with ICD-O-2/ICD-O-3 topography code C74.0 (adrenal cortex), classification 'malignant' and age at diagnosis $<20$ years were selected. Malignant adrenocortical tumors have been registered in the NCR since January 1, 1993, the cut-off date for inclusion was December 31, 2010 and follow-up was available for at least 2 years. Trained registrars from the NCR extracted clinical data from the medical records. Information on survival was included since vital statistics in the NCR are updated on a yearly basis through a link with the Municipal Personal Records Database, which contains personal files for everyone who lives or has lived in The Netherlands. Overall survival was calculated using the Kaplan-Meier estimator. The age-specific and age-standardized incidence rate for patients aged 0-20 years was calculated. The European standard population was used for standardization [European Standardized Rate (ESR)] (12). In The Netherlands, hospital pathology departments all participate in a nationwide network and registry of histopathology and cytopathology, the Dutch Pathology Registry (PALGA), thereby supplying NCR with data on patients and their corresponding diagnoses (13). Archival tumor slides were collected through PALGA. All available slides were reviewed by an expert pathologist (R.d.K.), and the Weiss score, Van Slooten and Wieneke index were determined. The Weiss score and Van Slooten index are widely used scoring systems to assess malignancy in (adult) adrenocortical tumors. We direct the reader to the literature for further details $(9,10,14)$. The Wieneke index is used to estimate malignancy in pediatric adrenocortical tumors (8). It consists of 9 macroscopical and microscopical criteria that are 
scored as present or absent. The presence of up to 2 criteria is supposed to be associated with benign clinical outcome, 3 criteria suggest uncertain/indeterminate malignant potential and the presence of 4 or more criteria is associated with poor clinical outcome. Disease staging was defined according to the ENSAT classification, i.e. stages I and II were defined as localized tumors $\leq 5 \mathrm{~cm}$ or $>5 \mathrm{~cm}$, respectively $\left(\mathrm{T}_{1} \mathrm{~N}_{0} \mathrm{M}_{0}\right.$ and $\mathrm{T}_{2} \mathrm{~N}_{0} \mathrm{M}_{0}$ ); stage III consisted of tumors that infiltrated surrounding tissue or displayed positive regional lymph nodes or tumor thrombus in the caval/renal vein $\left(\mathrm{T}_{3-4} \mathrm{~N}_{0-1} \mathrm{M}_{0}\right.$ or $\mathrm{T}_{1-2} \mathrm{~N}_{1} \mathrm{M}_{0}$ ); stage IV consisted of patients with distant metastases $\left(\mathrm{T}_{1-4} \mathrm{~N}_{0-1} \mathrm{M}_{1}\right)$.

In The Netherlands, anonymous use of clinical data and histological slides is permitted without explicit informed consent from the patient or legal representative. For the present study, this was confirmed by the Medical Research Ethics Committee of Máxima Medical Centre. Consent to review clinical data was obtained from the (former) local physician or his/her representative. The NCR's privacy committee and the board of PALGA agreed with the protocol.

\section{Results}

Demographics. Twelve patients were identified in the NCR. There were 8 females and 4 males, with a median age at diagnosis of 4.1 years (range 1.1-18.6, Table I). Seven patients had a left-sided tumor, 5 patients had a right-sided tumor. The diagnosis was histologically confirmed in all patients: 9 patients underwent therapeutic resection of the tumor, in 2 patients biopsy of the metastatic tumor tissue was performed and in 1 patient the diagnosis was histologically confirmed after autopsy.

The age-specific and age-standardized incidence rate for patients $<20$ years of age was 0.18 per million person-years between 1993 and 2010.

Clinical signs and symptoms. Data on clinical presentation were collected for 11 patients (medical records of the 12th patient could not be traced back). Ten patients presented with clinical signs of hormonal overproduction, which included moonface, acne, hirsutism, enlargement of the genitalia and progressively increased height (Table I). Abdominal complaints were reported in 5 patients. In 3 patients changes in behavior were reported by the parents. One patient showed hyperactive behavior, 1 patient presented with insomnia and excessive crying and 1 patient presented with an increased need for sleep.

Laboratory investigations revealed increased testosterone serum levels in 11 patients. Androgen precursors androstenedione and dehydroepiandrostenedione sulphate (DHEAS) were increased in 10 and 9 patients, respectively. Hypercortisolism was observed in 4 patients and estradiol was increased in 2 female patients.

Staging. Six patients presented with localized disease (stage I-II), 5 of whom were $\leq 4$ years of age. Three patients presented with locally advanced disease (stage III), 2 of whom were $\leq 4$ years of age. Distant metastases at presentation were reported in 3 patients, all aged $\geq 10$. One patient had both lung and liver metastases, 1 patient had liver metastases only and
Table II. Summary of the individual elements from Weiss score, Van Slooten and Wieneke index in 9 pediatric patients with adrenocortical carcinoma.

\begin{tabular}{lc} 
A, Weiss score criteria & \\
\hline Weiss score criteria & Total count \\
\hline High nuclear grade & 6 \\
Mitotic rate $\geq 5 / 50$ HPF & 9 \\
Atypical mitoses & 5 \\
Clear cells comprising <25\% of tumor & 8 \\
Diffuse architecture & 9 \\
Confluent necrosis & 6 \\
Invasion of venous structures & 4 \\
Invasion of sinusoidal structures & 5 \\
Invasion of capsule & 0 \\
Total Weiss score [median (range)] & $6(4-8)$ \\
\hline
\end{tabular}

B, Van Slooten index criteria

Van Slooten index (points per item)

criteria

Total count

Regressive changes (5.7) 6

Loss of normal structure (1.6) 9

Nuclear atypia (2.1)

6

Nuclear hyperchromasia (2.6) 5

Abnormal nucleoli (4.1) 5

Mitotic rate > 2/10 HPF (9.0) 9

Capsular and/or vascular invasion (3.3) 6

Total Van Slooten score [median (range)] 21.7 (15.3-28.4)

C, Wieneke-index criteria

Wieneke index criteria

Total count

Tumor weight $>400 \mathrm{~g}$ $2^{\mathrm{a}}$

Tumor size $>10.5 \mathrm{~cm}$

3

Extension into periadrenal tissue/organs

Invasion into vena cava

1

Venous invasion

0

Capsular invasion

4

Presence of necrosis

0

Mitotic rate $>15 / 20 \mathrm{HPF}$

6

Presence of atypical mitotic figures

4

Total Wieneke score [median (range)]

$2(1-6)$

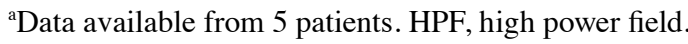

1 patient had lung metastases only. Of note, there were no patients aged $\geq 5$ and $<10$ years in the present population.

Therapy. Nine patients underwent surgical resection of the primary tumor. A microscopically radical resection was achieved in all patients except 1 in whom tumor cells were 
Table III. Summary of the individual disease staging, pathology findings and survival data in 12 pediatric patients with adrenocortical carcinoma.

\begin{tabular}{|c|c|c|c|c|c|c|c|c|c|c|c|c|}
\hline \multirow[b]{2}{*}{ Patient case no. } & \multicolumn{7}{|c|}{ Age $\leq 4$ years } & \multicolumn{5}{|c|}{ Age $\geq 5$ years } \\
\hline & 1 & 2 & 3 & 4 & 5 & 6 & 7 & 8 & 9 & 10 & 11 & 12 \\
\hline Stage of disease (ENSAT) & I & III & II & I & I & III & I & IV & IV & III & II & IV \\
\hline Tumor size (cm) & 3.5 & 15.0 & 6.0 & 5.0 & 4.0 & 10.0 & 2.0 & 12.0 & - & - & 16.0 & - \\
\hline Weiss score & 5 & 7 & 5 & 6 & 4 & 5 & 6 & 8 & - & - & 6 & - \\
\hline Van Slooten score & 15.3 & 21.7 & 19.4 & 23.7 & 20.4 & 22.2 & 22.7 & 21.7 & - & - & 28.4 & - \\
\hline Wieneke index & 1 & 6 & 2 & 2 & 1 & 2 & 1 & 5 & - & - & 5 & - \\
\hline Deceased & No & No & No & No & No & No & No & Yes & Yes & Yes & Yes & Yes \\
\hline Survival (months) & 57 & 179 & 92 & 178 & 97 & 159 & 91 & 38 & 6 & 1 & 25 & 3 \\
\hline
\end{tabular}

ENSAT, European Network for the Study of Adrenal Tumours. Stage I, $T_{1} N_{0} M_{0}$; stage II, $T_{2} N_{0} M_{0}$; stage III, $T_{1-2} N_{1} M_{0}$ or $T_{3-4} N_{0-1} M_{0} ;$ stage IV, $\mathrm{T}_{1-4} \mathrm{~N}_{0-1} \mathrm{M}_{1}$.

observed in the resection margin of the suprarenal vein. In another patient, resection was attempted yet the tumor turned out to be irresectable due to extensive growth into the vena cava $\left(\mathrm{T}_{4} \mathrm{~N}_{0} \mathrm{M}_{0}\right.$, stage III). In 2 patients resection was not performed due to an irresectable tumor combined with the presence of distant metastases (stage IV). None of the patients received adjuvant radiation therapy.

Mitotane therapy was administered to 3 patients who were diagnosed with metastasized disease. Two patients received additional multi-agent chemotherapy, i.e. cisplatin/etoposide/ doxorubicin (EDP) schedule according to the FIRM-ACT protocol (15). Mitotane dosing ranged from 4 to $12 \mathrm{~g} / \mathrm{day}$ (per 1.7-1.5 $\mathrm{m}^{2}$, respectively) and therapeutic plasma levels ( $>14 \mathrm{mg} / \mathrm{l}$ ) were reached in 1 patient. The best response of the 2 patients following combination therapy was partial response and stable disease, respectively. One of these patients was also treated with streptozotocin and etoposide/thalidomide/cyclophosphamide in a later stage. The third patient, who was on mitotane only, had progressive disease.

Pathology. Revision of the pathology slides was possible in 9 patients. In the remaining 3 patients representative pathology slides were not available; in 2 patients only a biopsy from a metastatic lesion was acquired and in 1 patient archival tissue acquired during autopsy showed necrosis only, while initially obtained material was not available anymore. Regarding the Weiss score, the criteria mitotic rate $[\geq 5 / 50$ high-power fields (HPFs)] and diffuse architecture, were present in all evaluated specimens. Invasion of the tumor capsule was not observed. The presence of other criteria is summarized in Table IIA. Regarding the Van Slooten index, the criteria 'loss of normal structure' and mitotic rate ( $>2 / 10 \mathrm{HPF}$ ) were present in all tumors examined. Other criteria are summarized in Table IIB.

Determination of the Wieneke index resulted in a median score of 2 (range 1-6) across 9 patients (Table IIC). It should be noted that the tumor weight was registered in 5 patients only. Among patients aged $\leq 4$ years at diagnosis $(n=7)$, 6 had a Wieneke index of $1(n=3)$ or $2(n=3)$ and 1 patient had a Wieneke index of 6 . Among patients aged $\geq 5$ years at diagnosis $(n=5), 2$ had a Wieneke index of 5 . The remaining
3 patients had been diagnosed with metastatic and/or invasive disease upon presentation, and also representative pathology slides of these patients were not available.

Survival. Survival of all 12 patients was described. All patients aged $\leq 4$ years at diagnosis survived $(n=7)$; the median follow-up was 97 months (range 57-179 months). In Table III, individual pathology findings and survival data are summarized. All patients aged $\geq 5$ years at diagnosis died from their disease $(n=5)$. The median survival in this subgroup was 6 months (range 0-38 months). One patient had a disease-free interval of 22 months after resection of the primary tumor followed by treatment with mitotane, EDP and eventually surgical resection of lung metastases. However, the lung metastases recurred and progressed under treatment with second and third line chemotherapy. The patient died 38 months following the primary diagnosis.

\section{Discussion}

The present study provides a population-based description of the epidemiology, clinical presentation, treatment and survival of all pediatric adrenocortical carcinoma (ACC) patients diagnosed in The Netherlands between 1993 and 2010. Patients $\leq 4$ years of age presented with clinically less advanced disease, even when the histology showed supposedly malignant characteristics. Accordingly, the overall survival in this subgroup was markedly better compared to the older patients. Clinical management in advanced ACC is adapted from adult practice in the absence of specific evidence regarding the pediatric population.

The incidence rate in the present study was comparable to the rate reported in a recent study with data of the SEER database, which presented an incidence rate of $0.21 / \mathrm{million}$ person years (2). To our knowledge, there are no other population-based reports of the incidence apart from studies on a population in southern Brazil, where the incidence was found to be up to 15 times greater due to a prevalent germline mutation of the TP53 gene (R337H TP53) (16). The incidence rate of 0.18 per million person-years in a population aged $<20$ years 


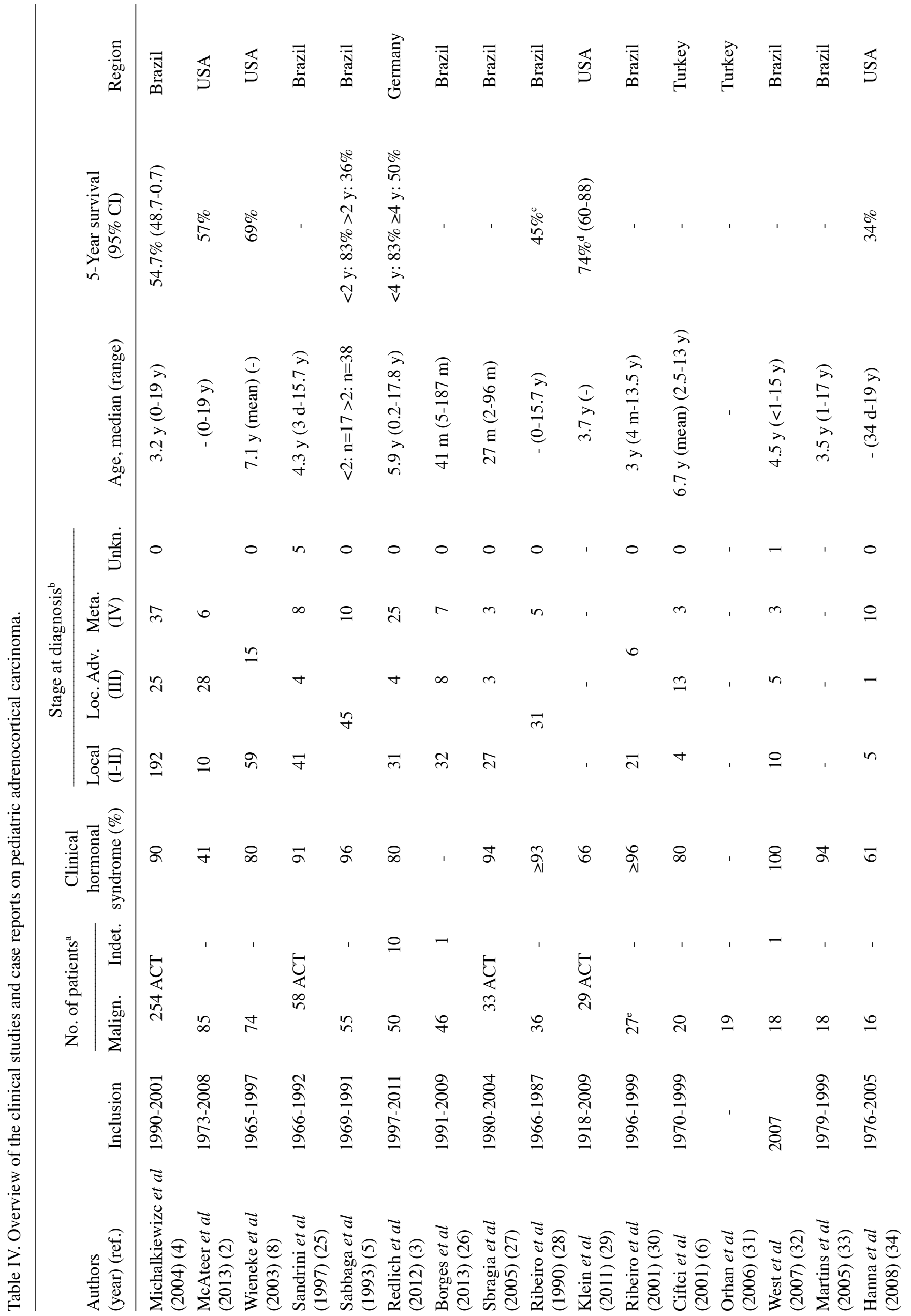




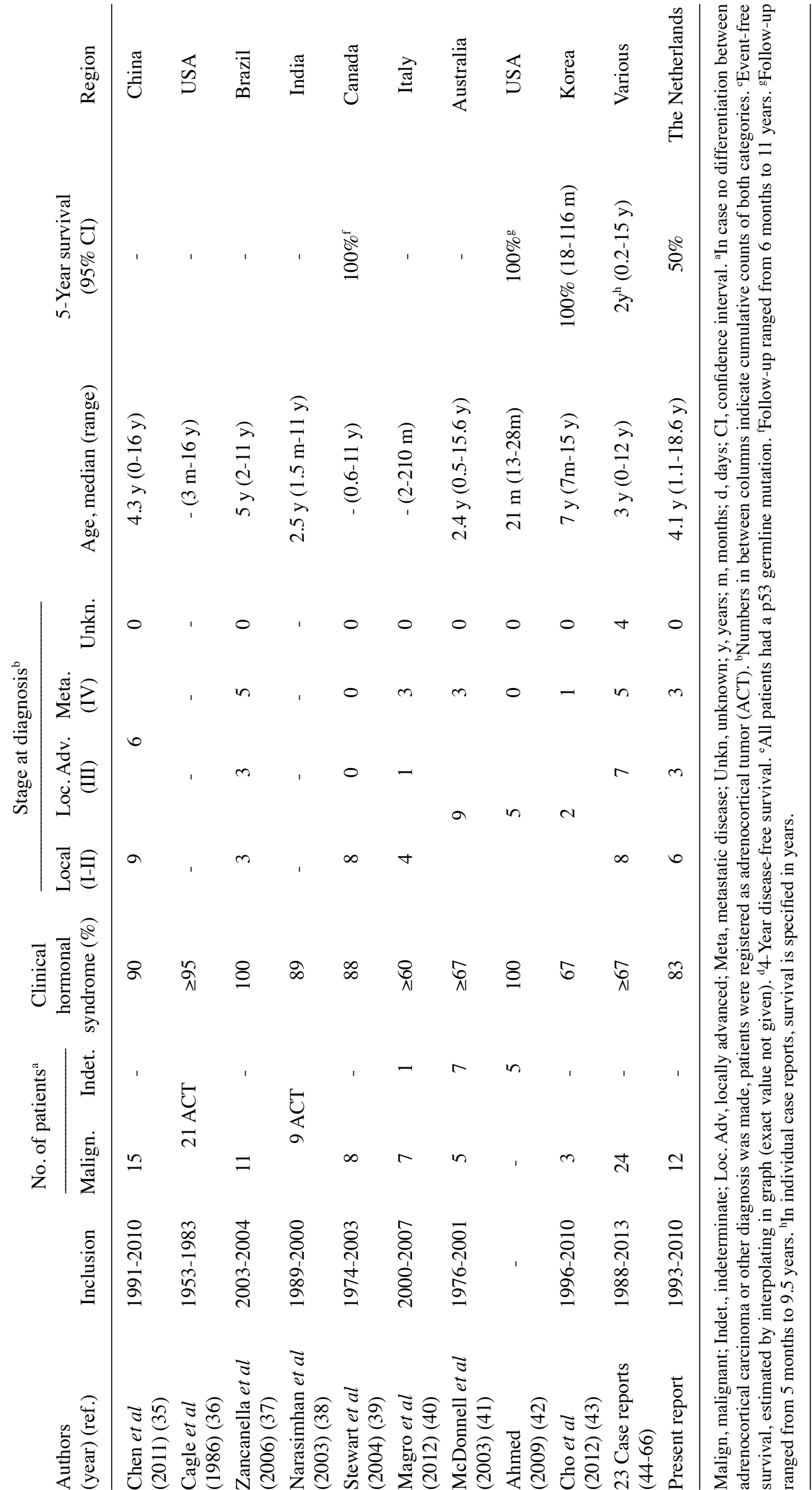


corresponds to less than one diagnosis per year in a Western country with 15.2-16.6 million inhabitants during the study period. Thus, pediatric ACC appears to be extremely rare in the Western world. Table IV provides a summary of all clinical studies and case reports regarding pediatric ACC that were found on PubMed. A total number of 910 patients (present report included) was found. However, overlap between several reports from the same region could not be excluded. When available, the presence of clinical signs of hormonal overproduction, stage of disease, age and survival of the included patients are displayed.

In the majority of our patients, clinical signs of hormonal overproduction such as virilization or Cushing's syndrome triggered the diagnostic work-up that led to the discovery of ACC. Similar findings were reported by other investigators. In the adult population this is typically the case in only $60 \%$ of patients, although autonomous hormone secretion is estimated to be present in at least $80 \%$ of adult patients $(17,18)$. Likely, symptomatic hormonal changes are more marked and thus sooner detected in children, whereas in adults such conditions may persist for a long period allowing tumors to grow and cause abdominal pain or discomfort.

We observed a striking correlation between clinical outcome and age at presentation. All patients $\leq 4$ years at diagnosis were alive without evidence of disease after at least a 5-year follow-up, whereas all patients aged 10 years or older died from their disease. The strong association between age and outcome was also reported in other series $(3-5,8)$. We acknowledge that in the present study disease stage was lower in the younger subgroup which may explain the better outcome, yet perhaps age and stage of disease are directly correlated. It has been suggested that ACC in patients under 4 years of age originates from fetal adrenal tissue and that it is essentially another type of cancer $(2,7)$. A histological substrate to substantiate this theory has not yet been found. Certain biochemical features such as increased expression of IGF-II and placental alkaline phosphatase (PLAP) that are characteristic of fetal adrenal tissue have been demonstrated in pediatric ACC as well, suggesting a relation between the two (19). However, these features do not seem to be unique to patients under 4 years of age (20). The age-related survival benefit does also seem to be present in patients from the Brazilian region where the p53 germline mutation is prevalent $(5,21)$. This could be compatible with extra-tumoral factors beneficial to survival in the youngest patients.

In our population, the Weiss score and Van Slooten index did not appear to be related to clinical outcome as they are in adults. It should be noted that low Weiss scores were not expected in our population since we only included tumors initially determined as carcinoma by local clinicians and pathologists. Nonetheless, a correlation between high Weiss scores $(>6)$ and adverse outcome as noted in adults was not observed (22). When the Wieneke index is attributed to our population, it appears this correlates better to clinical outcome than the Weiss score and Van Slooten index. Unfortunately, the limited sample size prevents a strong conclusion.

It was obvious (and expected) that complete surgical resection is the primary treatment of choice. We did not encounter patients in whom a diagnostic biopsy was performed before surgery was attempted. We expect that this is related to the high percentage of patients presenting with clinical symptoms, which suggests an indication for surgical resection anyway. We recommend to exercise restraint in performing biopsy of an adrenal tumor, particularly when there are signs of virilization or precocious puberty. In the adult population, biopsy is contra-indicated in patients without evidence of metastatic disease due to the high false-negative rate and the risk of complications (17).

Adjuvant treatment with mitotane and/or radiotherapy were not administered to any patient. Expectative management after successful surgery seems to be adequate in patients with localized disease and/or a low Wieneke index, which applies to all patients aged $\leq 4$ years at diagnosis in our study. In adult patients, adjuvant treatment with mitotane is currently being evaluated prospectively, while retrospective studies suggest it is indicated in patients with a Ki-67 index $>10 \%(23,24)$. Based on our data, it is not possible to make recommendations for patients with a high Wieneke index and age $\geq 5$ years. However, it is tempting to speculate that in the latter category the disease follows the 'adult' course and that similar clinical management should apply. Accordingly, adult clinical management was applied to 3 patients who presented with metastatic disease. Evidence on the efficacy of mitotane and cytotoxic chemotherapy in pediatric patients is scarce. In the GPOH-MET 97 trial, the duration of mitotane therapy and the achievement of therapeutic plasma levels were associated with increased overall survival (3). However, despite the commendable effort and outstanding organization of that study, the results were based on mitotane administration in 34 patients only. Interpretation is also complicated due to co-treatment with cytotoxic chemotherapy. Given the rarity of the disease, a prospective trial comparing different types of chemotherapy in pediatric ACC should be set up internationally in the same fashion as the FIRM-ACT-trial (15).

Our population-based study identified 12 pediatric ACC patients who were diagnosed in a time span of 18 years and who were treated in 5 different hospitals. It is intuitively logical to strive for concentration of care in a single centre due to a few patients with a rare and complex disease.

In conclusion, these nationwide data provide an assessment of pediatric ACC epidemiology, clinical management and survival in The Netherlands. The population-based incidence in a Western country was estimated at 0.18 /million personyears. The clinical outcome is remarkably better in patients $\leq 4$ years of age. This is in accordance with a less advanced stage of disease at presentation, yet contrasts with the presence of adverse histological characteristics in many of our young patients. In the absence of adequate evidence regarding pediatric ACC, clinical management in advanced disease is adapted from the adult practice. Due to the rarity of this disease, clinical trials are likely to succeed only in an international setting.

\section{References}

1. Kerkhofs TM, Verhoeven RH, Van der Zwan JM, et al: Adrenocortical carcinoma: a population-based study on incidence and survival in the Netherlands since 1993. Eur J Cancer 49: 2579-2586, 2013.

2. McAteer JP, Huaco JA and Gow KW: Predictors of survival in pediatric adrenocortical carcinoma: a Surveillance, Epidemiology, and End Results (SEER) program study. J Pediatr Surg 48: 1025-1031, 2013. 
3. Redlich A, Boxberger N, Strugala D, et al: Systemic treatment of adrenocortical carcinoma in children: data from the German GPOH-MET 97 trial. Klin Padiatr 224: 366-371, 2012.

4. Michalkiewicz E, Sandrini R, Figueiredo B, et al: Clinical and outcome characteristics of children with adrenocortical tumors: a report from the International Pediatric Adrenocortical Tumor Registry. J Clin Oncol 22: 838-845, 2004.

5. Sabbaga CC, Avilla SG, Schulz C, Garbers JC and Blucher D: Adrenocortical carcinoma in children: clinical aspects and prognosis. J Pediatr Surg 28: 841-843, 1993.

6. Ciftci AO, Senocak ME, Tanyel FC and Büyükpamukçu N: Adrenocortical tumors in children. J Pediatr Surg 36: 549-554, 2001.

7. Dehner LP and Hill DA: Adrenal cortical neoplasms in children: why so many carcinomas and yet so many survivors? Pediatr Dev Pathol 12: 284-291, 2009.

8. Wieneke JA, Thompson LD and Heffess CS: Adrenal cortical neoplasms in the pediatric population: a clinicopathologic and immunophenotypic analysis of 83 patients. Am J Surg Pathol 27 : 867-881,2003.

9. Weiss LM: Comparative histologic study of 43 metastasizing and nonmetastasizing adrenocortical tumors. Am J Surg Pathol 8 : 163-169, 1984.

10. van Slooten H, Schaberg A, Smeenk D and Moolenaar AJ: Morphologic characteristics of benign and malignant adrenocortical tumors. Cancer 55: 766-773, 1985.

11. Hubertus J, Boxberger N, Redlich A, von Schweinitz D and Vorwerk P: Surgical aspects in the treatment of adrenocortical carcinomas in children: data of the GPOH-MET 97 trial. Klin Padiatr 224: 143-147, 2012.

12. Doll R and Cook P: Summarizing indices for comparison of cancer incidence data. Int J Cancer 2: 269-279, 1967.

13. Casparie M, Tiebosch AT, Burger G, Blauwgeers H, van de Pol A, van Krieken JH and Meijer GA: Pathology databanking and biobanking in The Netherlands, a central role for PALGA the nationwide histopathology and cytopathology data network and archive. Cell Oncol 29: 19-24, 2007.

14. Weiss LM, Medeiros LJ and Vickery AL Jr: Pathologic features of prognostic significance in adrenocortical carcinoma. Am J Surg Pathol 13: 202-206, 1989.

15. Fassnacht M, Terzolo M, Allolio B, et al: Combination chemotherapy in advanced adrenocortical carcinoma. N Engl J Med 366: 2189-2197, 2012.

16. Faria AM and Almeida MQ: Differences in the molecular mechanisms of adrenocortical tumorigenesis between children and adults. Mol Cell Endocrinol 351: 52-57, 2012.

17. Fassnacht M, Kroiss $M$ and Allolio B: Update in adrenocortical carcinoma. J Clin Endocrinol Metab 98: 4551-4564, 2013

18. Fassnacht $\mathrm{M}$ and Allolio B: Clinical management of adrenocortical carcinoma. Best Pract Res Clin Endocrinol Metab 23: 273-289, 2009.

19. Boechat GA, Stinghen ST, Custódio G, et al: Placental alkaline phosphatase in pediatric adrenocortical cancer. J Pediatr Hematol Oncol 33: e149-e153, 2011.

20. Wilkin F, Gagné N, Paquette J, Oligny LL and Deal C: Pediatric adrenocortical tumors: molecular events leading to insulin-like growth factor II gene overexpression. J Clin Endocrinol Metab 85: 2048-2056, 2000.

21. Mastellaro MJ, Seindinger AL, Yunes JA, et al: Adrenocortical tumors in children: analysis of 105 patients from a single institution. The Fourth International Symposium on Adrenal Cancer, Paris, Abst, 2013.

22. Libe R, Borget I, Ronchi C, Terzolo M, Haaf M, Laino F, et al: Prognostic factors of advanced unresectable by stage III and IV ENS@T adrenocortical carcinomas (ACC). The 15th European Congress of Endocrinology, Copenhagen, 2013. (abstract Endocrine Abst 32 OC4.3. doi:10.1530/endoabs.32.OC4.3), 2013.

23. Terzolo M, Angeli A, Fassnacht M, et al: Adjuvant mitotane treatment for adrenocortical carcinoma. N Engl J Med 356: 2372-2380, 2007.

24. Terzolo M, Baudin E, Ardito A, et al: Mitotane levels predict the outcome of patients with adrenocortical carcinoma treated adjuvantly following radical resection. Eur J Endocrinol 169: 263-270, 2013

25. Sandrini R, Ribeiro RC and DeLacerda L: Childhood adrenocortical tumors. J Clin Endocrinol Metab 82: 2027-2031, 1997.

26. Borges KS, Moreno DA, Martinelli CE Jr, et al: Spindle assembly checkpoint gene expression in childhood adrenocortical tumors (ACT): overexpression of Aurora kinases A and B is associated with a poor prognosis. Pediatr Blood Cancer 60 : 1809-1816, 2013.
27. Sbragia L, Oliveira-Filho AG, Vassallo J, Pinto GA, GuerraJunior $G$ and Bustorff-Silva J: Adrenocortical tumors in Brazilian children: immunohistochemical markers and prognostic factors. Arch Pathol Lab Med 129: 1127-1131, 2005.

28. Ribeiro RC, Sandrini Neto RS, Schell MJ, Lacerda L, Sambaio GA and Cat I: adrenocortical carcinoma in children: a study of 40 cases. J Clin Oncol 8: 67-74, 1990.

29. Klein JD, Turner CG, Gray FL, et al: Adrenal cortical tumors in children: factors associated with poor outcome. J Pediatr Surg 46: 1201-1207, 2011.

30. Ribeiro RC, Sandrini F, Figueiredo B, et al: An inherited $p 53$ mutation that contributes in a tissue-specific manner to pediatric adrenal cortical carcinoma. Proc Natl Acad Sci USA 98: 9330-9335, 2001

31. Orhan D, Kale G, Cağlar M, Göğ üs S and Karaağaoğlu E: Histone mRNA in situ hybridization and Ki 67 immunohistochemistry in pediatric adrenocortical tumors. Virchows Arch 448: 591-596, 2006.

32. West AN, Neale GA, Pounds S, et al: Gene expression profiling of childhood adrenocortical tumors. Cancer Res 67: 600-608, 2007.

33. Martins AC, Cologna AJ, Tucci S Jr, Suaid HJ and Falconi RA: Clinical features and immunoexpression of p53, MIB-1 and proliferating cell nuclear antigen in adrenal neoplasms. J Urol 173: 2138-2142, 2005.

34. Hanna AM, Pham TH, Askegard-Giesmann JR, Grams JM, Iqbal CW, Stavlo P and Moir CR: Outcome of adrenocortical tumors in children. J Pediatr Surg 43: 843-849, 2008.

35. Chen QL, Su Z, Li YH, Ma HM, Chen HS and Du ML: Clinical characteristics of adrenocortical tumors in children. J Pediatr Endocrinol Metab 24: 535-541, 2011.

36. Cagle PT, Hough AJ, Pysher TJ, et al: Comparison of adrenal cortical tumors in children and adults. Cancer 57: 2235-2237, 1986.

37. Zancanella P, Pianovski MA, Oliveira BH, et al: Mitotane associated with cisplatin, etoposide, and doxorubicin in advanced childhood adrenocortical carcinoma: mitotane monitoring and tumor regression. J Pediatr Hematol Oncol 28: 513-524, 2006.

38. Narasimhan KL, Samujh R, Bhansali A, Marwaha RK, Chowdhary SK, Radotra BD and Rao KL: Adrenocortical tumors in childhood. Pediatr Surg Int 19: 432-435, 2003.

39. Stewart JN, Flageole H and Kavan P: A surgical approach to adrenocortical tumors in children: the mainstay of treatment. J Pediatr Surg 39: 759-763, 2004.

40. Magro G,Esposito G,Cecchetto G, et al: Pediatric adrenocortical tumors: morphological diagnostic criteria and immunohistochemical expression of matrix metalloproteinase type 2 and human leucocyte-associated antigen (HLA) class II antigens. Results from the Italian Pediatric Rare Tumor (TREP) Study project. Hum Pathol 43: 31-39, 2012.

41. McDonnell CM and Zacharin MR: Adrenal cortical tumours: 25 years' experience at the Royal Children's Hospital, Melbourne. J Paediatr Child Health 39: 682-685, 2003.

42. Ahmed AA: Adrenocortical neoplasms in young children: age as a prognostic factor. Ann Clin Lab Sci 39: 277-282, 2009.

43. Cho MJ, Kim DY, Kim SC, Kim TH and Kim IK: Adrenocortical tumors in children 18 years old and younger. J Korean Surg Soc 82: 246-250, 2012.

44. Pusantisampan T, Sangkhathat S, Kayasut K, Kanngurn S, Jaruratanasirikul S, Chotsampancharoen T and Kritsaneepaiboon S: Cushing's syndrome in an infant secondary to malignant adrenocortical tumors with somatic mutation of beta-catenin. Pediatr Dev Pathol 13: 238-242, 2010.

45. Lima Lde O, Lerario AM, Alencar GA, et al: Clinical and molecular aspects of a pediatric metachronous adrenocortical tumor. Arq Bras Endocrinol Metabol 55: 72-77, 2011.

46. Aricò M, Bossi G, Livieri C, Raiteri E and Severi F: Partial response after intensive chemotherapy for adrenal cortical carcinoma in a child. Med Pediatr Oncol 20: 246-248, 1992.

47. Delaney HM, Prauner RD and Person DA: Germline p53 mutation in a Micronesian child with adrenocortical carcinoma and subsequent osteosarcoma. J Pediatr Hematol Oncol 30: 803-806, 2008

48. De León DD, Lange BJ, Walterhouse D and Moshang T: Long-term (15 years) outcome in an infant with metastatic adrenocortical carcinoma. J Clin Endocrinol Metab 87: 4452-4456, 2002.

49. Fiszer-Maliszewska L, Kazanowska B, Padzik J; Regional Blood Transfusion Center: p53 Tetramerization domain mutations: germline R342X and R342P, and somatic R337G identified in pediatric patients with Li-Fraumeni syndrome and a child with adrenocortical carcinoma. Fam Cancer 8: 541-546, 2009. 
50. Fudge EB, von Allmen D, Volmar KE and Calikoglu AS: Cushing syndrome in a 6-month-old infant due to adrenocortical tumor. Int J Pediatr Endocrinol 2009: 168749, 2009.

51. Ghazizadeh F, Ebadi M, Alavi S, Arzanian M, Shamsian B and Jadali F: Adrenocortical carcinoma presenting with heterosexual pseudoprecocious puberty shortly after birth: case report and review. Ecancermedicalscience 7: 289, 2013.

52. Godil MA, Atlas MP, Parker RI, et al: Metastatic congenital adrenocortical carcinoma: a case report with tumor remission at 3 1/2 years. J Clin Endocrinol Metab 85: 3964-3967, 2000.

53. Hah JO: Intensive chemotherapy with autologous PBSCT for advanced adrenocortical carcinoma in a child. J Pediatr Hematol Oncol 30: 332-334, 2008

54. Hara F, Kishikawa T, Tomishige H, Nishikawa O, Nishida Y and Kongo M: A child with adrenocortical carcinoma who underwent percutaneous ethanol injection therapy for liver metastasis. J Pediatr Surg 38: 1237-1240, 2003.

55. Inage E, Saito M, Saito Y, Takata O, Fujimura J, Yamataka A and Shimizu T: Contralateral pleural recurrence of adrenocortical carcinoma after surgical resection. Pediatr Int 53: 600-603, 2011

56. Kanmaz T, Demirbilek S, Ozardali I, Safali M, Guran S and Yucesan S: Nonfunctioning adrenocortical carcinoma in a child. Pediatr Pathol Mol Med 22: 405-410, 2003.

57. Khayat CM and Johnston DL: Rhabdomyosarcoma, osteosarcoma, and adrenocortical carcinoma in a child with a germline p53 mutation. Pediatr Blood Cancer 43: 683-686, 2004.

58. Ko JH, Lee HS, Hong J and Hwang JS: Virilizing adrenocortical carcinoma in a child with Turner syndrome and somatic TP53 gene mutation. Eur J Pediatr 169: 501-504, 2010.
59. Lin MT, Shieh JJ, Chang JH, Chang SW, Chen TC and Hsu WH: Early detection of adrenocortical carcinoma in a child with Li-Fraumeni syndrome. Pediatr Blood Cancer 52: 541-544, 2009.

60. Mertens F, Kullendorff CM, Moell C, Alumets J and Mandahl N: Complex karyotype in a childhood adrenocortical carcinoma. Cancer Genet Cytogenet 105: 190-192, 1998.

61. Miyoshi Y, Oue T, Oowari M, et al: A case of pediatric virilizing adrenocortical tumor resulting in hypothalamic-pituitary activation and central precocious puberty following surgical removal. Endocr J 56: 975-982, 2009.

62. Pivnick EK, Furman WL, Velagaleti GV, Jenkins JJ, Chase NA and Ribeiro RC: Simultaneous adrenocortical carcinoma and ganglioneuroblastoma in a child with Turner syndrome and germline p53 mutation. J Med Genet 35: 328-332, 1998.

63. Romaguera RL, Minagar A, Bruce JH, et al: Adrenocortical carcinoma with cerebral metastasis in a child: case report and review of the literature. Clin Neurol Neurosurg 103: 46-50, 2001.

64. Sorgo W, Meyer D, Rodens K, Homoki J, Heinze E, Heymer B and Siebenmann R: Testosterone-secreting adrenocortical tumor in a pubertal girl. Case report and review of the literature. Horm Res 30: 217-223, 1988

65. Wagner AS, Fleitz JM and Kleinschmidt-Demasters BK: Pediatric adrenal cortical carcinoma: brain metastases and relationship to NF-1, case reports and review of the literature. J Neurooncol 75: 127-133, 2005.

66. Wong LM, Li CH, Chan OK, Shek CC and Kwong NS: A 12-year-old Chinese girl with Cushing syndrome and virilization due to adrenocortical carcinoma. J Pediatr Endocrinol Metab 24: 193-196, 2011. 